\title{
Implication of MicroRNAs in the Pathophysiology of Cardiac and Vascular Smooth Muscle Cells
}

\author{
Valérie Metzinger-Le Meuth, Eléonore M'Baya-Moutoula, \\ Fatiha Taibi, Ziad Massy and Laurent Metzinger
}

Additional information is available at the end of the chapter

http://dx.doi.org/10.5772/47770

\section{Introduction}

In the last 10 years, microRNAs (miRNAs) have emerged as critical regulators of numerous physiological and pathological mechanisms [1-2], including cardiac and vascular smooth muscle cell (VSMC) plasticity [3-5]. These small molecules (approx. 20 to 25 nucleotides) comprise a novel and abundant class of endogenous interfering RNAs. More than 1500 miRNAs are now listed by dedicated internet databases such as miRBase, Tarbase, MicroRNA.org or miRdb (See sub-chapter II for URL adresses). They are transcribed and matured, in a process known as miRNA biogenesis [6] which starts with the transcription of a larger RNA product, called pri-miRNA, by the RNA polymerase II in the vast majority of cases. Pri-miRNA, which is a few hundred to a few thousand nucleotides long, is then submitted to cleavage in the nucleus by a specific RNase III (Drosha) and its protein partner, DiGeorge syndrome critical region 8 (DGCR8), near the base of the miRNA hairpin stem. This process releases a pre-miRNA hairpin (of approx. 60 to $70 \mathrm{nt}$ ). The pre-miRNA is then released in the cytoplasm where it is recognized and cleaved within its stems by the Dicer RNase III and its protein partners. This results in a double stranded RNA, known as the miRNA/miRNA* duplex (approx. $22 \mathrm{bp}$ ). This complex is unwound to single strands. One strand (guiding strand / mature miRNA) is incorporated in the RNA-induced-silencing complex (RISC) that contains Argonaute 2 (Ago2), another endonuclease, the other strand is usually rapidly degraded. Finally, the RISC complex carries the mature miRNA to its target messenger RNAs (mRNAs), which results in gene silencing, in a post-transcriptional manner [7]. Figure 1 shows a representative example of the biogenesis of miR-143 and miR-145, which are the main miRNAs expressed in smooth muscle cells. 


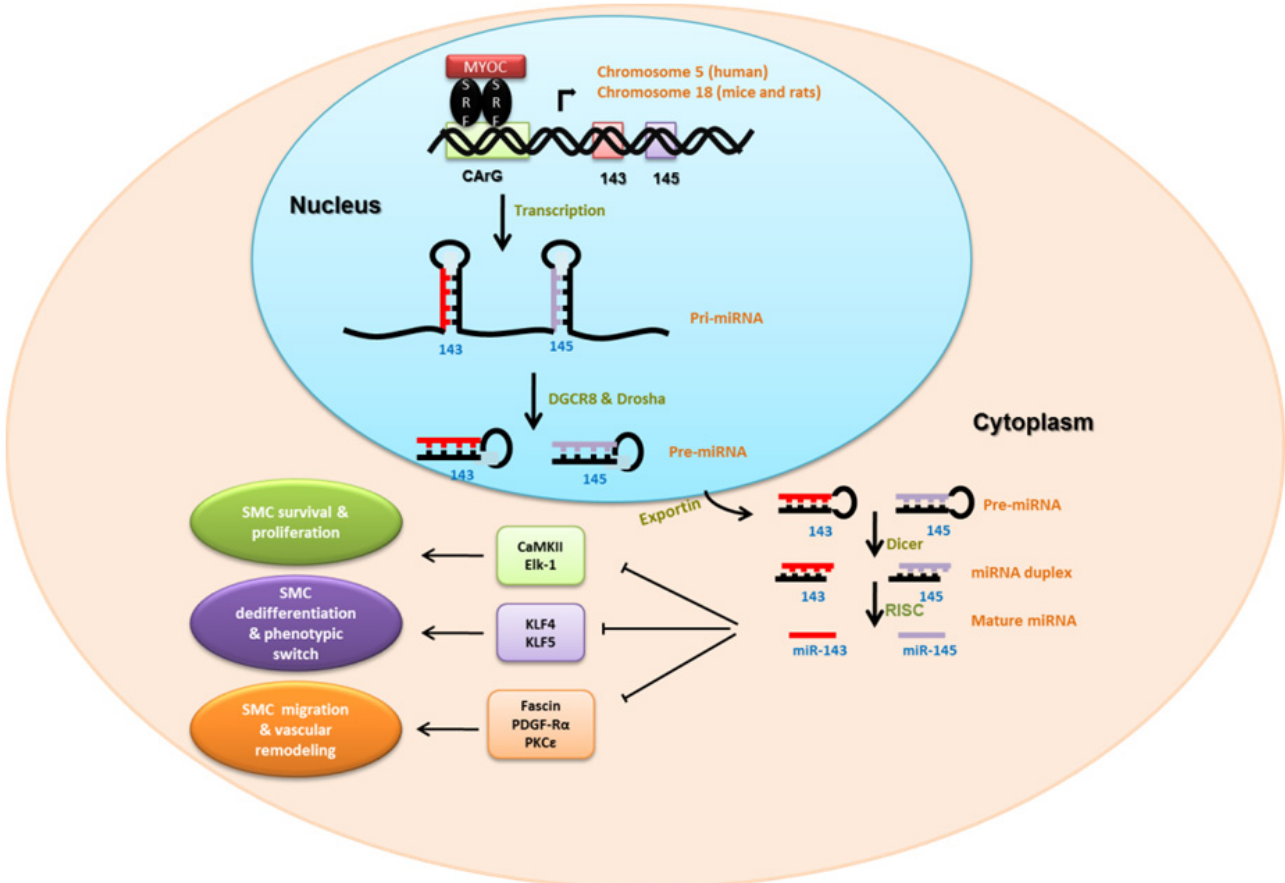

Figure 1. Schematic representation of the miR-143/145 cluster biogenesis, which expresses the main miRNAs in vascular smooth muscle. The transcription factor Myocardin in complex with its cofactor Serum Response Factor (SRF) binds CArG box-containing promoters, which then activates the transcription of the miR-143/145 cluster. MiR-143 and 145 are cotranscribed as a single pri-miRNA transcript. The Drosha and DGCR8 (DiGeorge Syndrome Critical Region 8) complex processes the primiRNA into a hairpin-structured pre-miRNA. The pre-miRNAs corresponding to miR-143 and 145 are exported by a nucleocytoplasmic shuttle protein known as exportin, from the nucleus to the cytoplasm and are then cleaved by the Dicer complex into miRNA duplexes. The miRNA duplexes are finally unwound to obtain the mature miR-143 and miR-145, which are incorporated into the RNA-induced silencing complex (RISC) and bind various mRNA targets in their 3' untranslated region. In vascular smooth muscle cells (VSMCs), miR-143 and 145 inhibit the expression of CaMKII ( $\mathrm{Ca}^{2+} /$ calmodulindependent protein kinases II) and Elk-1 (E twenty-six (ETS)-like transcription factor 1), which induces a repression of VSMC survival and proliferation. Also, the miR-143 and 145 inhibit the expression of Fascin, PDGF-R $\alpha$ (Platelet-derived growth factor receptor $\alpha$ ) and PKC $\varepsilon$ (Protein Kinase C $\varepsilon$ ) which induces a repression of VSMC migration and of the vascular remodeling. Finally, miR-143 and 145 also inhibit the expression of KLF4 and 5 which are repressors of Myocardin activity. As a consequence, VSMC differentiation is maintained.Adapted from [3].

Determining how the RISC complex carries a specific miRNA to its target mRNAs, and thus regulates gene expression, remains an intense field of research. The most important feature in the miRNA sequence is a short but critical region called the seed sequence, which is only 7 nts long, and most of the times, located in nucleotides in positions 2 to 8 of the miRNA. The base-pairing uses canonical Watson-Crick complementarity. Conversely, this small stretch of nucleic acids is a useful tool to classify miRNA into families based on shared seed 
sequences. Since the miRNA seed is so short, each miRNA can potentially bind hundreds of target mRNAs when one considers the large number of possible binding sites in mRNA regulatory sequences. This is one of the reasons why one single miRNA can regulate the expression of multiple target genes, by binding as many as several hundreds of mRNA targets. This clearly shows the role of these small RNAs in the intricate tapestry of gene regulations. Another, foremost reason for this complexity is that miRNAs, outside of the seed region, bind their mRNA targets mostly as imperfect complements. Similarly, one mRNA can be regulated by several miRNAs. All this further explains how the 1500 miRNAs known to date are able to regulate the expression of approximately one third of the human genes. Thus, microRNAs are likely to impact multiple mechanisms of gene regulation and developmental pathways, by using extensive regulatory gene expression networks [1-2].

The current paradigm states that miRNAs act mostly by inhibiting the translation of their target mRNAs, rather than by inducing their degradation. Bartel's team has however recently challenged that view by showing that, in a vast majority of cases, mammalian microRNAs act by destabilizing their target mRNAs and by decreasing their levels [8]. No matter the case, a wide consensus agrees that miRNAs are posttranscriptional regulators which bind to their target mRNAs, mostly in their 3' Untranslated Region (UTR). Note, however, that recent unbiased studies have shown that, in some particular cases, miRNAs bind the coding region or 5'UTR of respective target mRNAs ([9-11].

The miRNA nomenclature is remarkably standardized and straightforward [12]: the prefix "mir" is followed by a dash and an assigned number, reflecting the prevalence of discovery, to experimentally confirmed miRNAs. Gene is referred to in italic, eg mir-143. The pre-miRNA is designated by the suffix mir-, eg mir-143. Finally, the mature miRNA is abbreviated miR-, eg miR-143. MiRNAs with similar sequences / structure except for 1-2 nts, will be assigned a supplementary letter, eg miR-29a, miR-29b, miR-29c and often originate from the same gene. Different loci will produce different pre-miRNAs, but yield a mature miRNA with the precise same sequence. In this case, the nomenclature miR-1-1, miR-1-2 etc will be used. In some cases, one pre-miRNA will result in two different mature miRNAs, one from the 5-prime stem and one originating from the 3-prime stem. They will be designated by the suffixes miR-142-5p and miR-142-3p. Species can also be taken into consideration: hsa-miR refers to Homo sapiens miRNAs, mmu-miRNAs to Mus musculus, etc.

Mature miRNA sequences and pathways are remarkably preserved throughout phylogeny. Also, the evolutionary complexity of multicellular organisms positively correlates with the number of miRNA genes, their expression, and the diversity of their targets [13]. This remarkable conservation is used by most miRNA target prediction algorithms. These dedicated softwares use a standardized method to evaluate interactions between miRNAs and their specific target mRNAs based on (1) complementarity between mRNA 3' UTR and miRNA seed sequence and (2) the degree of conservation of miRNA across species (see subchapter 2 for url adresses). The end result is straightforward: the higher the conservation, the higher the score given. 


\section{Current methods for studying miRNAs: Functional analysis}

Various techniques have been developed over the last decade to quantify the expression of miRNAs and study their function (extensively reviewed in [14]). Figure 2 exposes the most widely used methods. Northern blotting was first used to quantify miRNAs, but this tedious technique, relying on radioactive labeling, was rapidly replaced by the much more convenient qRT-PCR. Two interchanging chemistries can be used for qPCR: (1) Sybr Green, which is often associated with a modified oligo(dT) technique, and the adjunction of an universal primer for reverse transcription which enables reverse transcription of all transcripts within an RNA sample; therefore, target miRNA and normalizing mRNA can be analyzed from the same RT reaction; or (2) Taqman chemistry, in association with the use of stem-loop miRNA-specific RT primers to produce cDNA, with the advantage of additional specificity. Both give accurate results. Each method has its own assets and setbacks. Technically speaking, the modified oligo(dT) method requires only a single RT reaction to reverse transcribe both miRNA and its target mRNAs and is less time consuming. Both techniques have been optimized and developed to screen most of known miRNAs in one experiment. Indeed, analysis of high-throughput miRNA expression remains a challenge since the number of miRNAs continues to increase with in silico prediction and experimental verification. Oligonucleotide microchip (microarray) was first widely used for high throughput miRNA screening, but a novel miRNA expression profiling approach, quantitative RT-PCR array (qPCR-array) is now rapidly gaining ground. Comparison between microarray and qPCR-array indicated a superior sensitivity and specificity of qPCR-array [15], and qPCR arrays are now rapidly becoming the method of choice.

Over-expressing or inhibiting miRNA activity, using RNA constructs, and examining the resulting phenotypic effects is crucial for understanding microRNA involvement, both in vitro and in vivo. For that, solutions are readily available for in vitro use [16]. Knock-in is most of the time induced by the addition of pre-miR precursors of a particular miRNA, often nicknamed "mimics". Alternatively, viral vectors have been developed by various industrials, most of them relying on modified lentivirus or adeno-associated virus (AAV). On the other hand, knock-down is classically induced by transfection of so-called "antagomiRs", which have been developed to interfere with expression of a specific miRNA. These synthetic RNA inhibitors incorporate the reverse complement of the mature miRNA (which represents here the target site). They are chemically modified to enhance binding affinity and decrease nucleolytic cleavage by the RISC complex and degradation by other RNAses. The last years have also seen the development of miRNAs sponges, which are equivalent to the endogenous sponges described below (see sub-chapter V). These long transcripts contain repeated regions complementary to specific miRNAs which will bind them instead of their dedicated mRNA targets, thus resulting in miRNA silencing. All these techniques can also be implemented in vivo, in various animal models.

Finally, classic knock-out genetic strategies can be applied to miRNA genes [17]. MiRNAprocessing proteins such as Dicer, Dgcr8, Drosha or Ago2 are essential for viability in mice. Knock-out mice individually lacking these key miRNA-processing genes die during early 
gestation with severe developmental defects, including in vessels and heart. However, conditional murine knockout of these genes have been developed recently and offer valuable tools to study miRNA importance, including in the cardiac organ. Also, one can obtain animals models totally devoid of the miRNA of interest. We describe below the interesting example of mice knock-outed of the most widely expressed vascular miRNAs, miR-143 and miR-145 (see subchapter III, [18-20]).
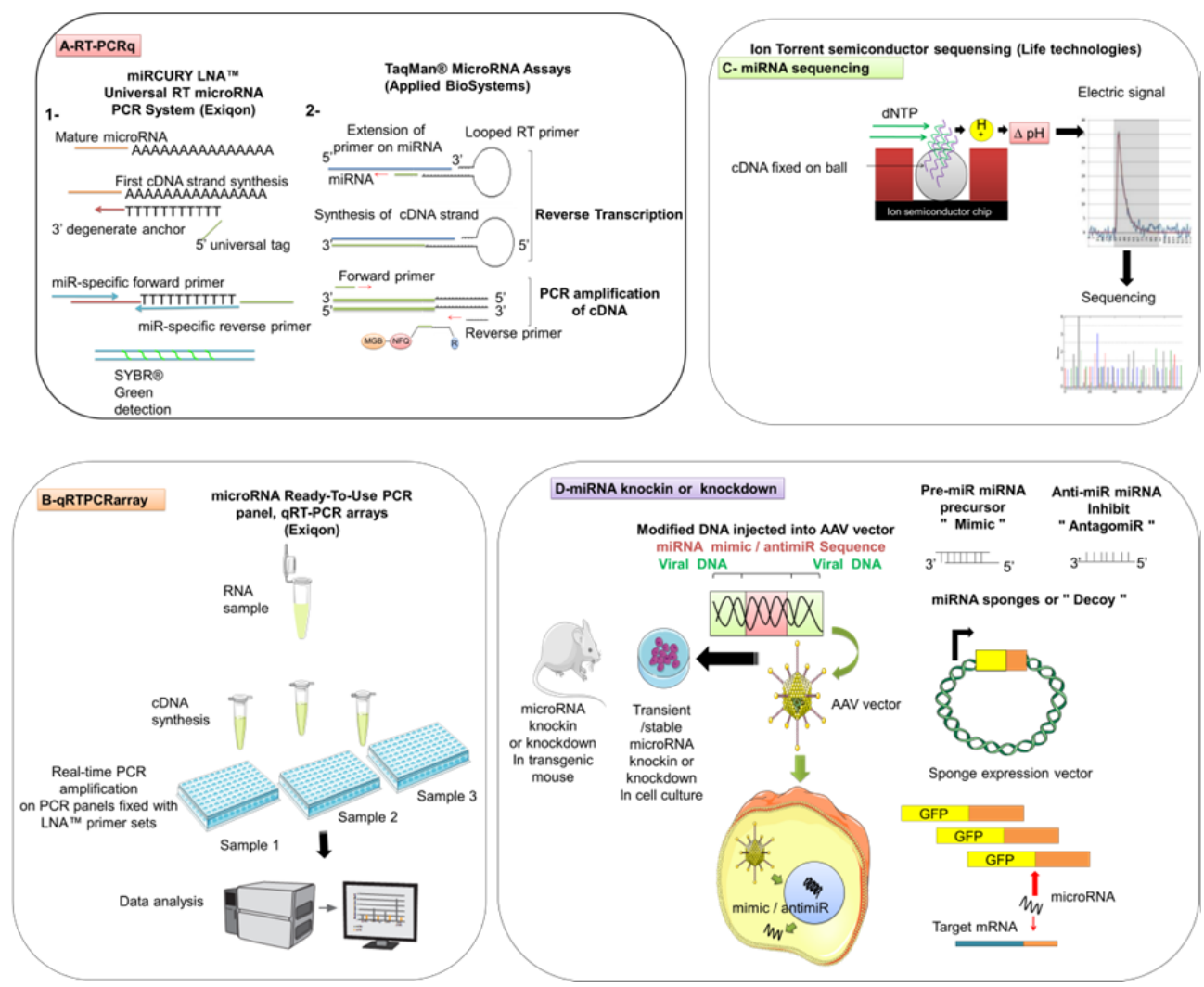

A- Schematic outline of microRNA RT-qPCR Systemq. (1) A poly-A tail is added to the mature microRNA template. cDNA is synthesized using a poly-T primer with a $3^{\prime}$ degenerate anchor and a $5^{\prime}$ universal tag. The cDNA template is then amplified using microRNA-specific and $\mathrm{LNA}^{\mathrm{TM}}$-enhanced forward and reverse primers. SYBRß Green is used for detection . (2) Taqman chemistry with the use of specific stem loop RT primers, and of an internal Taqman probe for qPCR quantitation.

B-qRT-PCR arrays: The microRNA PCR array protocol is a two-part protocol consisting of, 1- First-strand cDNA synthesis, 2- Real-time PCR amplification. Two 384-well plates enable to quantitate more than 700 miRNA in one experiment.

C-High throughpout sequencing. Nucleotides flow sequentially over Ion semiconductor chip- Direct detection of natural DNA extension- A few seconds per incorporation

$D$ - miRNA sponges interfere with miRNA function. Sponges are ectopically expressed or artificial RNAs that contain multiple miRNA target sites. These target sites compete miRNAs away from their natural mRNA targets. miRNA sponges are suitable for use in a variety of experimental systems, including cultured cells and transgenic animals.

Figure 2. Methods currently used to study miRNA expression and function. 
Websites are dedicated to identification of microRNA gene targets, and experimental validation of these in silico data: miRBase (http://www.mirbase.org/), Tarbase (diana.cslab.ece.ntua.gr/DianaToolsNew/index.php?r=tarbase/index),

MicroRNA.org (http://www.microrna.org/microrna/home.do) or miRdb (http://mirdb.org/miRDB). They were described above. Unfortunately, as of today, the results given by the various websites are often very different from each other and the informations must therefore be subject to careful scrutiny. An interesting complement is provided by Patrocles (http://www.patrocles.org/). This software attends to the referencing of polymorphisms (Single nucleotide polymorphisms, SNP, mostly) and the interactions between target genes and relevant miRNAs in seven vertebrate species. Significant progress will certainly come from this sort of research efforts in the next few years since it is now increasingly clear that non-coding SNPs provide a potential mechanism for transmission of phenotypes and diseases. Finally, biochemical approaches, using affinity purification, are also being developed for direct empirical detection of miRNA associating with the 3'UTR of mRNA targets [21].

\section{MicroRNAs are implicated in the pathophysiology of vascular smooth muscle cells}

VSMCs are not terminally differentiated cells like skeletal and cardiac muscle cells. They have a remarkable plasticity which allows them to undergo phenotypic modulation inducing a switch from a "synthetic" to a "contractile" phenotype, in response to physiological and pathological environmental cues. On one hand, vascular injury or growth factors like PDGF provoke VSMC dedifferentiation which, as a consequence, transdifferentiates the cells into a highly migratory and proliferative ("synthetic") phenotype necessary for vascular repair or angiogenesis. On another hand, Transforming Growth Factor- $\beta$ (TGF- $\beta$ ) and its related family member Bone Morphogenetic Protein 4 (BMP4) promote differentiation into a less migratory and less proliferative phenotype known as the "contractile" phenotype. This VSMC phenotypic modulation, called transdifferentiation, is characterized by significant changes in cellular gene expression pattern. In particular, high expression of VSMC-specific genes, such as smooth muscle $\alpha$-actin (SM $\alpha \mathrm{A})$, calponin $1(\mathrm{CNN})$, and SM22 $\alpha$ (SM22) are associated with the contractile phenotype. Transcription of contractile genes is regulated by SRF through a DNA sequence motif known as the $\mathrm{CArG}$ box $\left(\mathrm{CC}(\mathrm{A} / \mathrm{T})_{6} \mathrm{GG}\right)$ which is present in the promoter of VSMC-specific genes. A coactivator (and binding partner) of SRF, myocardin, activates VSMC expression of key contractile genes ([22-23].

The recent emerging role of miRNAs in gene expression regulation via gene silencing (through mRNA degradation or translation inhibition) suggests a role for these small nucleic acids in VSMC phenotypic regulation. Indeed, numerous publications have documented their importance through in vitro and in vivo studies in the cardiac and vascular biology fields and their related diseases [24]. This important role of miRNAs in VSMC development, differentiation, and related pathologies has been emphasized by two independent teams [2526] that independently showed that knock-outing the miRNA processing enzyme Dicer in murine VSMCs provokes severe vascular abnormalities, resulting in embryonic lethality. Among vascular miRNAs, miR-143 and miR-145 are the most documented to date, and will 
be explored in greatest detail. They are the most highly expressed miRNAs in smooth muscle cells, and their down-regulation is directly associated with a phenotypic switch from contractile, i.e. fully differentiated to synthetic, i.e. proliferative, VSMCs. Other miRNAs such as miR-21, miR-221 and miR-222 also have demonstrated roles in VSMC differentiation. Their functions in smooth muscle will also be described. See Figure 3A for a pictorial representation of their roles in VSMCs.
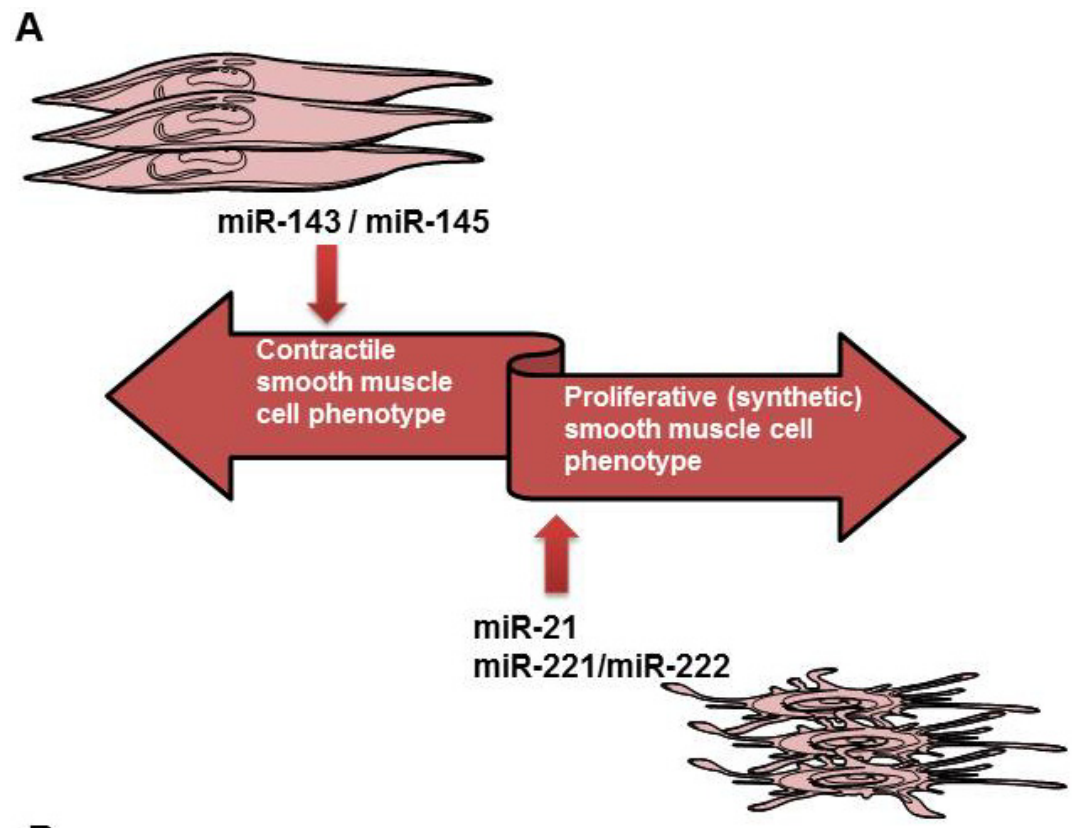

B
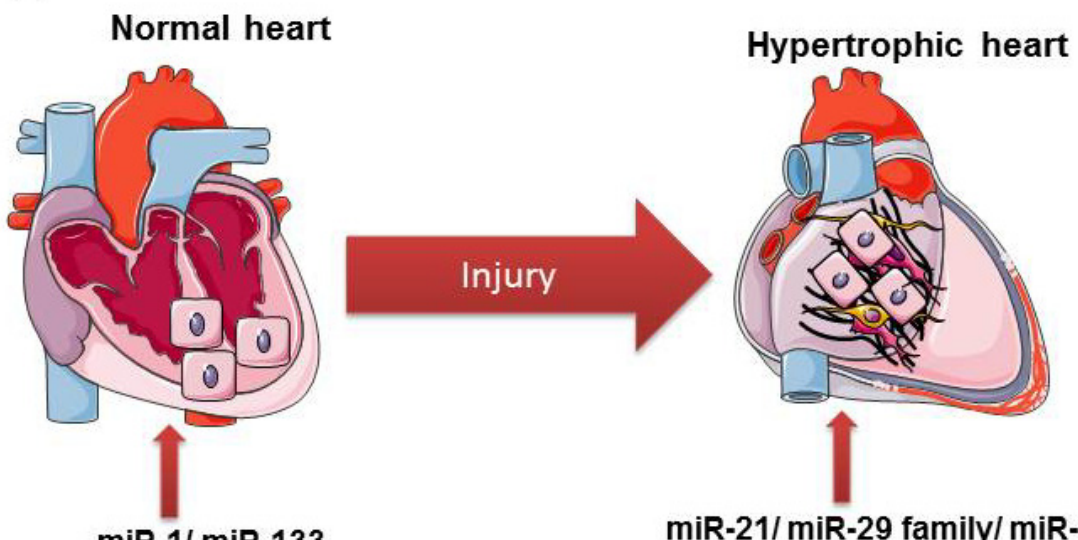

miR-1/ miR-133

miR-21/ miR-29 family/ miR-208

Figure 3. (A) Main micro-RNAs involved in the regulation of smooth muscle cell phenotype, including transdifferentiation from synthetic to contractile phenotype and (B) main micro-RNAs involved in cardiac muscle cell physiopathology. 


\subsection{The miR-143/145 cluster}

The bicistronic unit which encodes miR-143 and miR-145 is critical for maintaining the VSMC contractile phenotype. For example, miR-143 and miR-145 are down-regulated in synthetic VSMCs [19-20] when VSMC dedifferentiation is induced by PDGF and during neointimal formation [27]. On the opposite, TGF $\beta 1$ (Transforming Growth Factor 1), a strong activator of VSMC differentiation, stimulates both miRNAs expression in a dose- and time-dependent manner [27]. The transcription of miR-143/145 is under the control of two independent signaling pathways: SRF/myocardin/Nkx2.5 and Jag-1/Notch signaling [28]. The expression of miR-143/145 is drastically reduced in several models of vascular disease: carotid artery ligation injury in mouse, carotid balloon-injury in rat, and ApoE Knock-out mice [27]. In miR-143 or miR-145 KO mice, abnormal vascular tone and reduced contractile activity have been detected but VSMCs are functional [29]. Moreover, miR-143/145 levels are decreased in aortas from patients with aortic aneurism and lower circulating levels are detected in the serum of patients with coronary artery disease [20-22]. Overexpression of miR145 induced lower neointima formation in balloon-injuried arteries [27].

Dimmeler and colleagues showed recently an example of vesicle-mediated miRNA transfer between human vascular endothelial cells and human aortic SMCs [30]. Blood vessels exposed to laminar blood flow undergo high shear stress. It is known that under shear stress conditions vascular endothelial cells overexpress the transcription factor Krüppel-like factor 2 (KLF2) which in turn induces up-regulation of miR-143 and miR-145. MiR-143/145 are transported in extracellular vesicles such as exosomes and they reduced the expression of miR-143 and miR-145 specific targets in co-cultured VSMCs. Additionally, the authors showed that extracellular vesicles derived from KLF2-expressing endothelial cells decrease atherosclerotic lesion formation in the ApoE KO mice kept on a high fat diet [30].

\subsection{MiR-21, $\mathrm{miR}-221$, and $\mathrm{miR}-222$}

In contrast to miR-143/145, miR-21, miR-221, and miR-222 are up-regulated in neointimal lesions.

TGF- $\beta$ and its related family member BMP4 promote contractile gene expression and VSMC differentiation. Interestingly, they induce the transcription of the miR-143/145 cluster and promote also an increased expression of miR-21 post-transcriptionally. The critical target of miR-21 that is down-regulated in this process is programmed cell death 4 [22]. As a consequence, miR-21 induces VSMCs transdifferentiation to the contractile phenotype in response to BMP4 and TGF $\beta$ [31]. Additionally, miR-21 promotes VSMC proliferation and reduces apoptosis [32]. These miR-21 actions were confirmed in balloon-injured rat carotid arteries [33]. Moreover, knock-down of mir-21 using antisense oligonucleotides (antogomiRs) in the rat decreases vascular remodeling following balloon injury in carotid arteries [32]. Although an increase in differentiation is usually coupled to a decrease in proliferation, this is not necessarily the case in VSMCs. MiR-21 indeed targets a diverse set of genes and mediates differential biological outcomes depending on the cellular context [22].

Mir-221 and miR-222 genes are clustered on the X chromosome and share a common seed sequence. Some reports indicate that they are transcribed from a common promoter [34]. 
Mir-221 and miR-222 contribute to VSMC dedifferentiation from the differentiated / contractile to the undifferentiated / synthetic phenotype and thus to increased cellular proliferation. Indeed, miR-221 and miR-222 are strongly elevated in vivo in VSMC following balloon injury of the vessel. Knock-down of mir-221 and miR-222 in the vessel reduced VSMC proliferation and neointimal lesion formation after angioplasty. Mir-221 and miR-222 are important for PDGF-cell mediated proliferation, by repressing tyrosine kinase c-kit, p57Kip2 and the cyclin-dependent kinase inhibitor p27Kip1. Interestingly, inhibition of c-kit reduced the expression of myocardin [32,35]. Overexpression of miR-221 induces an important decrease of myocardin expression, even if this miRNA does not target myocardin directly. Instead, it is the down regulation of c-Kit that is responsible for the up-regulation of myocardin. MiR-221 overexpression also increases during VSMC migration but the targets are still unknown. All these findings provide an example of the potential of one miRNA to mediate various cellular outcomes by regulating multiple targets [22,32].

\section{MicroRNAs are implicated in the pathophysiology of cardiac muscle cells}

Cardiovascular pathologies represent the prevalent causes of human morbidity and mortality in the Western hemisphere. As a consequence, a vast number of research groups consider that studying heart molecular and cellular characteristics is a major step in order to develop novel diagnostic and therapeutic strategies and to counteract cardiovascular diseases. It is now clear that miRNAs are an important part of the complex transcriptional and posttranscriptional regulatory circuit essential for the homeostasis of the cardiac tissue. They are powerful modulators in virtually all aspects of cardiac biology, from cardiac development to cardiomyocyte survival and hypertrophy, which we will now describe in more detail in this subchapter.

In the recent literature, more than a hundred microRNAs have been described as stably expressed in the cardiac tissue [36-38]. However, the vast majority (90\%) of these miRNAs are represented by no more than 18 miRNAs in the mature murine organ. Even more remarkable is the fact that all these 18 miRNAs show an altered expression in pathological conditions, including coronary artery diseases and cardiomyopathies. Interestingly, it has been shown that a strong characteristic of these various models of cardiovascular disorders is the re-expression of a fetal cardiac miRNA program. This miRNA expression will finally trigger the over-expression of several fetal proteins, such as the atrial and brain natriuretic factor genes and the fetal isoform of the $\beta$-Myosin Heavy Chain gene ( $\beta \mathrm{MHC}$ ). Exploring further how miRNAs regulate gene expression in the heart will thus provide us with unique mechanistic insights into cardiac diseases. We will now describe in further details the miRNAs which have been the most implicated in the process. See Figure 3B for a pictorial representation of their roles in cardiac muscle.

\subsection{Anti-hypertrophic miRNAs}

Muscle miRNAs, such as miR-1 and miR-133, are integrated into myogenic regulatory networks: their expression is under the transcriptional and posttranscriptional control of myo- 
genic factors, and they in turn have widespread control of the muscle gene expression program. Recent studies demonstrated that both miR-1 and miR-133 are significantly downregulated in hypertrophic and failing hearts. They play major roles in the development of cardiac hypertrophy, and have thus been nicknamed anti-hypertrophic miRNAs. In addition, miR-1 and the related miRNA miR-133 arise from a common precursor RNA which is regulated by the transcription factors Serum Response Factor (SRF) and Myocyte Enhancer Factor 2 (MEF2, [37]), which clearly suggest their importance in an intricate cardiac regulatory network.

The mature miR-1 transcript is the product of two genes, miR-1-1 and miR1-2, and it is now proven that its elevation induces arrhythmia in cardiac disease states. Its expression is specific for both cardiac and skeletal muscle. Overexpression of mature miR-1 in rat exacerbates cardiac arrhythmia whereas its knock-down by an antagomiR in the same animal, in the infarcted heart relieves arrhythmogenesis [39]. MiR-1 is also overexpressed in individuals with coronary artery disease. Part of miR-1 action is mediated by down regulation of connexin 43 and the inward rectifier K channel (Kir2.1, [39]). Another important role of miR-1 is to modulate cardiac excitation-contraction coupling by selectively increasing phosphorylation of the L-type and RyR2 channels via disrupting localization of PP2A activity to these channels [40]. Determining plasma levels of miR-1, using qPCR techniques (see subchapters II and VI) can be used as a sensitive biomarker for myocardial infarction and its expression is strongly down-regulated in hearts from patients afflicted with myocardial infraction compared to healthy adult hearts [41].

There are three known mir-133 genes: mir-133a-1, mir-133a-2 and mir-133b found on chromosomes 18, 20 and 6 respectively. In the human genome, all three genes encode miRNA with identical mature sequence [42]. Actually, miR-133a-1 and miR-133a-2 are each expressed bicistronically with miR-1-1 and miR1-2. Knockdown experiments of miR-133 gave at first puzzling results: in vitro overexpression of miR-133 or miR-1 inhibited cardiac hypertrophy while infusing mice with antagomiRs against the mature miR-133 sequence induced cardiac hypertrophy [43]. On the other hand, genetic models with knockout of either mir-133a gene did not display significant cardiac pathologies, or actually any phenotype. However, deleting both mir-133a genes resulted in a drastic phenotype: ectopic expression of cardiac-specific markers genes in VSMCs, embryonic lethality, and aberrant proliferation of cardiac muscle cells [37]. The phenotypic difference between mice treated by antagomiRs at the adult stage, and genetic models which have been deprived from miRNAs from conception clearly shows the limits of both models. The sum of these studies however clearly emphasizes the role of the miR-133 mature sequence in cardiac muscle biology. On a mechanistic side, Horie et al. [44] have shown a direct role of miR-133 in cardiomyocyte glucose transport: overexpression of the miRNA decreased levels of the glucose transporter GLUT4 and reduced insulin-induced glucose uptake. Additionally, this increase of miR-133 reduced Krüppel-like transcription factor 15 (KLF15) expression, which induces GLUT4 expression.

\subsection{Pro-hypertrophic miRNAs}

The role of mir-21 in cardiac modeling and pathophysiology is clearly controversed. MiR-21 inhibition by antagomir strategies was first reported as causing an alleviation of murine 
cardiac hypertrophy $[38,45]$. A divergence arose when the first team attributed this prohypertrophic effect to an effect on cardiomyocytes [38] whereas the second team claimed the primary site of miR-21 action was actually cardiac fibroblasts [45]. In contrast to both team results, Cheng et al. [46] reported that miR-21 was indeed increased by fourfold in hypertrophic mouse hearts, but that modulating miR-21 via antisense depletion had a significant negative effect on cardiomyocyte hypertrophy. Finally, Patrick et al. [47] found that a genetic deletion of the mir-21 gene results in mice with a normal phenotype that did not respond differently to normal littermates when exposed to cardiac stress conditions. Also, in the same study, LNA-modified antagomiRs specific for miR-21 did not block a remodeling response of the murine heart to stress conditions. The authors concluded that, although miR-21 is highly up-regulated during cardiac remodeling, it is not essential for cardiac hypertrophy, a disease state associated with fibrosis in response to heart injury. Nonetheless, miR-21 is a miRNA of interest in the cardiac field, at least as an innovative biomarker, since it is almost undetectable in the healthy heart, but is strongly overexpressed in cardiac pathologies.

The human miR-29 family of microRNAs is encoded by two gene clusters. As a consequence, three matures members exist: miR-29a, miR-29b, and miR-29c. In this instance, the miR-29 family has been shown to be expressed in both cardiac fibroblasts and cardiomyocytes [48]. In these cell types, sixteen of their targets are extracellular matrix genes. This clearly shows a striking example of a single microRNA mature sequence which is capable to target a large group of functionally related genes. As a consequence, miR-29 expression induces strong antifibrotic effects in heart and other tissues. MiR-29s have also been shown to be pro-apoptotic and involved in cell differentiation. Acute myocardial infarction due to coronary artery occlusion also results in a decrease of the expression of the miR-29 family in the region of the fibrotic scar [48]. Using up- and down-regulation of miR-29, the same authors showed that this miRNA regulates the expression of collagens, and as a result the fibrotic response. Finally, the miR-29 family has also been shown to down-regulate elastin and other extracellular matrix (ECM) genes implicated in elastogenesis [49]. Jones et al. [50] have examined miRNA expression using qPCR in aortic tissue collected from patients with ascending thoracic aortic aneurysm and shown that miR-29a expression is correlated with cardiac tissue proteolytic degradation and aortic size. These last results show the interest of determining specific miRNA levels in human diagnostic.

Another miRNA of interest in the cardiac field of investigation is miR-208a, which is expressed strictly in the heart. Mir-208a overexpression in transgenic mice induces hypertrophic growth of the cardiac muscle and induces arrhythmias. This hypertrophic growth is concomitant with fibrosis and a decrease of contractility, which results from downregulation of the faster isoform, $\alpha$-myosin heavy chain $(\alpha-\mathrm{MHC})$ and up-regulation of the fetal specific, slower isoform, $\beta$-MHC [51-52]. Thus, cardiac-specific overexpression of miR208a induces cardiac remodeling and regulates the expression of hypertrophic proteins, including $\beta$-MHC. Conversely, the same authors showed that genetic deletion of miR-208a in mouse induces a decrease of $\beta$-MHC. Additionally, miR-208 targets other proteins, such as thyroid hormone-associated protein 1 and myostatin 2, which are both inhibitors of mus- 
cle growth and hypertrophy, with for final consequence hypertrophic cardiac growth. MiR208a is also strongly up-regulated in the diseased human heart as detected in biopsies from patients afflicted with myocardial infarction [41]. Also, miR-208a is not detected in plasma from healthy patients, but is raised to a detectable level as soon as $1 \mathrm{~h}$ after coronary artery occlusion [53]. This result is important, since it clearly shows that, at least for this miRNA, plasma levels reflect tissue amounts, and thus that miRNA are strong candidates as noninvasive biomarkers (see subchapter VI for more information on this topic).

\section{The miRNA regulators: Who watches the watchmen?}

Expressional patterns of miRNAs vary according to organs and their developmental stages. Indeed, several transcriptional and post-transcriptional processes control the levels of mature miRNAs. The study of these regulatory mechanisms is still in its very early steps. We will review here what is known, starting with other non-coding RNAs which are as long as miRNAs are short, we will proceed with transcription factors, and finally explore how cells are able to communicate with each other, using microRNAs.

In the last few years, it has been shown that long non-coding RNAs act as miRNA sponges and/or competing endogenous RNAs, are able to regulate miRNA function by binding complementarily with them, thus competing with their dedicated mRNAs targets, and thereby to impose an additional level of post-transcriptional regulation. Little is known about the mechanisms of action of these exciting new regulatory RNAs in muscle cells. A groundbreaking result came from Cesana et al [54]: they have identified a long non coding RNA, called linc-MD1, in the skeletal muscle. linc-MD1 is stably expressed in mouse and human myoblasts, and controls the myogenesis program by binding, and thus "sponging" two instrumental miRNAs, miR-133 and miR-135, which in turn regulate transcription factors that activate muscle-specific gene expression. By "inhibiting the inhibitors", linc-MD1 accelerates myogenesis. Interestingly, this RNA's expression is strongly reduced in Duchenne muscular dystrophy, a genetic disorder which is characterized by a drastic reduction of myoblasts. No equivalent of linc-MD1 has yet been described in smooth muscle biogenesis or in cardiogenesis but one can strongly guess that they will be identified in the forseeable future.

Several transcription factors have been characterized as miRNA regulators in smooth, cardiac and skeletal muscle cells, thus revealing novel mechanisms underlying VSMC differentiation. Myocardin is the best characterized in VSMCs and cardiac cells [55]. Myocardin, with its co-activator Serum Response Factor (SRF), is a cardiac- and muscle specific trans-acting protein, and a master regulator of the smooth muscle phenotype. It has been shown that this transcription factor regulates several miRNAs in VSMCs. It induces miR-1 expression, which in turn inhibits VSMC proliferation, and increases their differentiation, by targeting Pim-1, a serine/threonine kinase [56]. Similarly, myocardin represses versican, a chondroitin sulfate proteoglycan of the extra-cellular matrix that is produced by synthetic VSMCs and promotes VSMC migration and proliferation, by inducing the expression of miR-143, a miR instrumental in VSMC differentiation [57]. SRF has been shown to regulate the expression of 
several mIRs, including miR-1, miR-133a and miR-21 [58]. Interestingly, myocardin coactivator SRF regulates microRNA biogenesis, specifically the transcription of primicroRNA, thereby affecting the mature microRNA level, by binding to the proximal promoter region of miR genes. Transforming Growth Factor- $\beta 1$ (TGF $\beta 1$ ), another known stimulus capable of inducing VSMC differentiation, has also been shown to induce both miR-143 and miR-145 in human coronary artery SMCs [59]. We have already discussed the importance of transcription factors SRF and MEF4 in the regulation of miR-1 and miR-133 (see subchapter 5). Finally, although skeletal muscle is outside of the topic of this chapter, it is interesting to note that another important muscle-specific transcription factor, MyoD, impacts miR-1 and miR-206 expressions, with strong consequences on myoblast apoptosis levels [60]. Although it has not been shown yet, one can speculate that similar systems exist in smooth muscle and cardiac muscle cells.

Decay mechanisms affecting miRNAs in order to regulate their expression are not well understood. However, new notions have recently been put to the forefront: it seems that changes in cellular density and cell adhesion mechanisms affect rapidly miRNAs expression [61]. When cells are grown at low density or after cell splitting, some miRNAs are rapidly degraded while others remain unaffected. This rapid, and yet unexplained, degradation of persistent regulatory molecules such as miRNAs may facilitate cellular plasticity and remodeling in response to various stresses.

Wang et al. [62] have recently shown that several human cell lines from various origins (glioblastoma, hepatocytes, lung bronchial epithelium, pulmonary fibroblasts, alveolar basal epithelial cells) actively release miRNAs in a short time period of time (approx. $1 \mathrm{~h}$ ) after serum deprivation. Thus, one can hypothesize that, at least some, exported miRNAs are used for cell-to-cell communication. More studies will of course be needed to determine exactly how miRNAs are specifically targeted to relevant target cells, and what information is transduced. It will also be important to determine why evolution has selected several different means of transportation for miRNAs: protein complexes, exosomes, Microvesicles, High Density Lipoprotein (HDL) or apoptotic bodies (Figure 4). For example, miRNA complexed with proteins, could be targeted to specific cell surface receptors, and miRNAs inside vesicles to others targets. All these recent results ask important questions about cell-to-cell communication mediated by miRNAs, and raise the possibility that a yet undiscovered biological information transduction system exists, and could be important to explain many biological processes including development, differentiation, and stress response. In cardiovascular diseases, for example, the general decrease in circulating miRNAs detected in patients with CAD might be caused by a disregulation of this miRNA trafficking system in atherosclerotic lesions or in the infarcted myocardium.

\section{MiRNAs: New biomarkers in vascular and cardiac diseases}

Being instrumental players in the fine-tuning of gene regulation networks, microRNAs have significant diagnostic and prognostic value, as biomarkers of disease etiology and progression. Until recently, however, miRNA quantitation and usefulness as a biomarker 
was dependent on the availability of the pathological tissue. This was not a major setback for the diagnosis of cancer, where biopsies were readily available in most cases, but proved to be serious concern when dealing with heart or vascular pathologies. Very recently, these concerns were alleviated when several teams showed that miRNAs can be detected and precisely measured in human blood (eg $[63,64])$. These papers, showing a stable presence of miRNA in human plasma, came as a surprise. Indeed, any researcher having experience with RNA work considers ribonucleic acids as fragile and unable to survive in a liquid like serum which contains a wealth of specific and non-specific degrading enzymes.

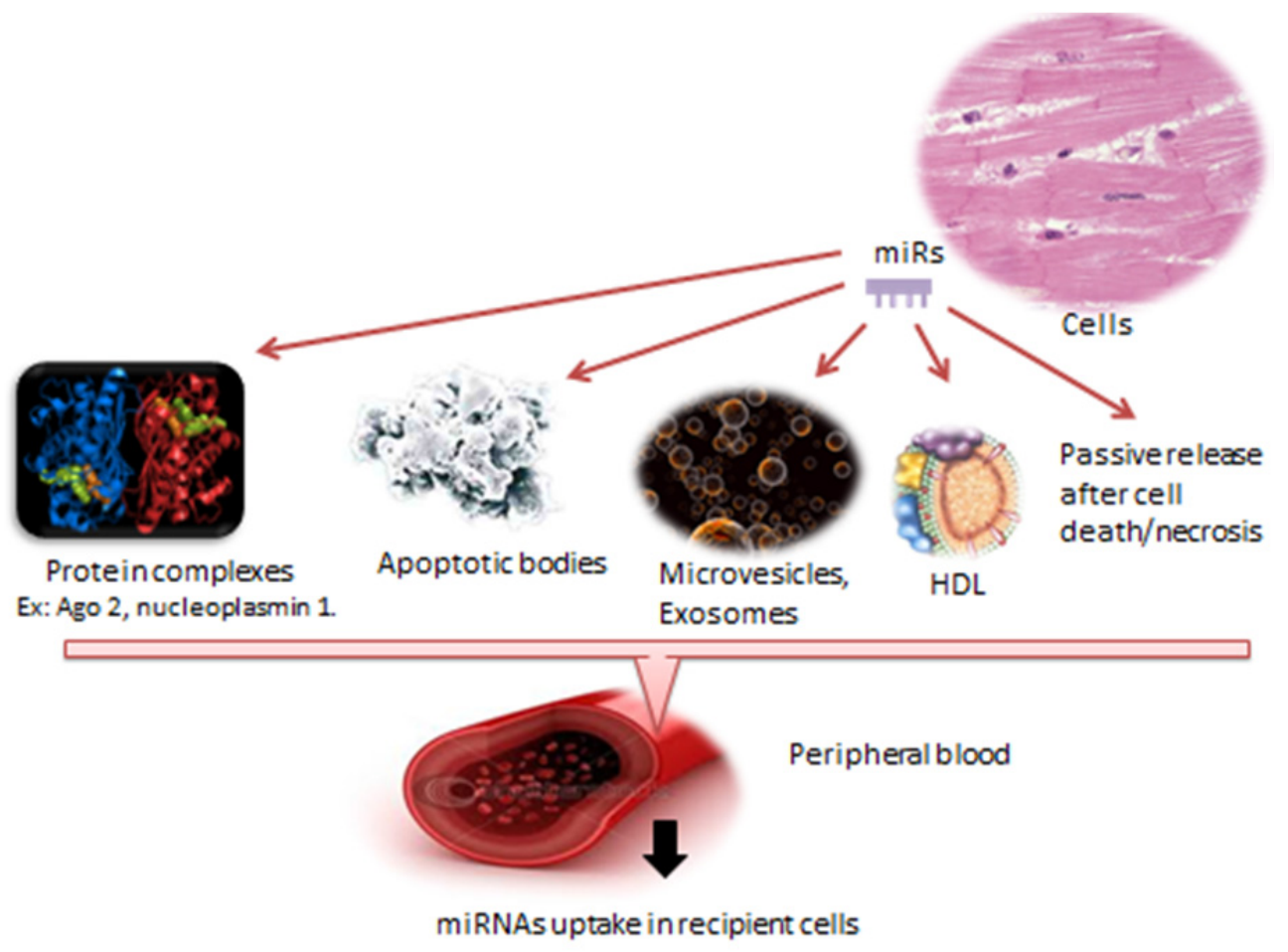

Figure 4. The various mechanisms of miRNA release from cells in the peripheral blood circulation and their uptake in recipient cells. Ago2 Argonaute 2; HDL High density Lipoprotein.

Stephanie Dimmeler's pioneer studies show that miRNA can be detected in the serum of patients with coronary artery diseases (CAD) and that their levels are altered in patient's serum when compared to healthy counterparts [65] [65-66]. MiRNAs are thus prime candidates as novel non-invasive biomarkers in cardiovascular diseases, which can be measured in routine clinical diagnosis. The main question here is which endogenous referent genes to use as this is instrumental in qPCR. In cardiovascular disease studies, various endogenous circulating miRNAs (eg miR-17-5p, miR-454, U6 or RNU6b) have been used for normalization of circulating miRNAs, but the use of spiked-in miRNAs, i.e. adding a known amount of exogenous non-human miRNA, (eg synthetic Caenhorabditis elegans miR- 
39) is now increasingly common as the experimenter knows clearly the amount of the referent miRNA, and no further experimental bias is added [66].

An important question is the exact localization of miRNAs in the bloodstream. They exist in a highly stable, extracellular form and are remarkably persistent in the RNase-rich environment of blood. The first model postulates that circulating miRNAs are protected by encapsulation in membrane-bound vesicles such as exosomes, phagosomes, apoptotic bodies...[65-66] Arroyo et al. [67] have however recently challenged this view: they used a combination of differential centrifugation and size-exclusion chromatography and showed that circulating miRNAs cofractionate mostly with protein complexes rather than with vesicles, in human plasma and serum. Even more surprising was the fact that the main miRNA binding partner was Ago2, the key effector protein of miRNA-mediated silencing, which is considered as a cytosolic protein. Ago2 seems to be one of the factors protecting circulating miRNAs from plasma RNases, since purified miRNAs, devoid of protein partners, were sensitive to RNase treatment. Figure 4 summarizes the different hypotheses that have been put forward to explain how miRNAs can be secreted and exported in human blood.

Goren et al. [68] have very recently published that four miRNAs, miR-22, miR-92b, miR-320a and miR-423-5p were significantly increased in the serum of patients with heart failure. By relying on a signature derived from the expression of these miRNAs, the authors were able to discriminate between systolic heart failure patients and healthy controls with a sensitivity and specificity of $90 \%$. Moreover, there was a significant correlation with important clinical prognostic parameters such as an elevated serum natriuretic peptide and a wide QRS. Other recent papers have highlighted the interest of determining their levels in serum and other body fluids, including urine, feces and saliva [69-70]. This forebodes well for the increasing usefulness of specific miRNA expression as non-invasive biomarkers.

\section{Potential of miRNAs as innovative drug targets}

In the last decade, the increasing interest in small RNAs has triggered the arrival of innovative drug targets on the pharmaceutical market. Among these small RNAs, miRNAs provide perhaps the most promising new opportunities for developing new compounds, especially with the recent advances in anti-miRNA chemistry. On one hand, therapeutic nucleic acids can be administered using lentivirus-mediated antagomir expression, which induces a stable knockdown phenotype for a specific miRNA [71-72]. On the other hand, the vast majority of antimiRs used in trials are in fact altered locked nucleic acids (LNA), also known as inaccessible RNA (reviewed in [73]). The canonic nucleic acid ribose sugar backbone is modified with an extra bridge connecting the 2' oxygen and 4' carbon [74]. This conformation enhances base stacking and backbone pre-organization, which will significantly enhance the hybridization properties for the compounds. These poly-anionic molecules tend to distribute broadly but also to accumulate in liver, kidney and phagocytes. They are highly hydrophilic, with a molecular weight ranging from 2 to $6 \mathrm{kD}$. For the moment, routes of administration used are essentially intravenous and subcutaneous injections [75-76]. One has however got to keep in 
mind that developing innovative drugs is risky, represents a tremendous cost in resources, time, etc., and should not be undertaken lightly.

A first clinical trial, in this post-genome era, is under way in human patients affected by viral hepatitis C. Phase IIa results of this promising trial, focusing on the liver-specific miR122 [77], aims to develop the related drug called Miravirsen, developed by Santaris Pharma $\mathrm{A} / \mathrm{S}$ as a LNA antagomir, and thus to antagonize miR-122, which is instrumental for Hepatitis $C$ virus $C(\mathrm{HCV})$ infection. Langford et al. [78] had already shown in primates that a LNA-specific for miR-122 was able to suppress HCV viremia, with no evidence of viral resistance or side effects in the treated animals. These promising results are confirmed in humans and show that using an antagomir approach induces a decrease of the patient's viral load, and that this revolutionary treatment is less toxic and more effective than current medicine (http://www.santaris.com/news/2011/11/05/santaris-pharma-phase-2a-datamiravirsen-shows-dose-dependent-prolonged-viral-reduct), perhaps due to the specificity brought by RNA strand complementarity.

Concerning cardiovascular diseases, we will now focus on the expanding interest of miRNAs in cardiovascular molecular medicine, and the various studies that have been undertaken, on animal models, for the time being.

The important role of the miR-29 family of microRNAs has already been evoked in this chapter (see subchapter V). A promising study dealt with their effects in two murine models of abdominal aortic aneurysm (AAA) (porcine pancreatic elastase [PPE] infusion model in C57BL/6 mice and the AngII infusion model in ApoE-/- mice). Antagomirs against miR-29b was administered in vivo under the form of LNA. This resulted in an increase of collagen expression [79], which resulted in an early fibrotic response in the aortic wall and an actual reduction of AAA progression in both models. Conversely, overexpression of miR-29b using lentiviral vectors resulted in an aggravation of AAA, and a premature rupture of the aortic wall. This miRNA is thus a promising target for creating an innovative treatment for AAA.

Matkovich et al. [80] have shown that over-expression of miR-133a in the heart of transgenic mice prevented TAC-associated miR-133a downregulation and improved myocardial fibrosis and diastolic function. In another, more exotic, model, Yin et al. [81] have shown that miR-133 restricts injury-induced cardiomyocyte proliferation.

Very recently, miR-33, although not specific for cardiac or vascular tissues, has gained a lot of attention in atherosclerosis treatment [82]. Both miR-33a and miR-33b target the adenosine triphosphate-binding cassette transporter A1 (ABCA1), an important regulator of high-density lipoprotein (HDL) synthesis and reverse cholesterol transport in a murine model. Inhibiting miR-33 using two different methods (overexpression of dedicated lentiviral particles or injection of LNA antagomiRs) led to an up-regulation of ABCA1 and importantly to an increase of cholesterol influx and concomitant increase in the levels of HDL, and thus of atheroprotective effects. These authors show thus clearly that increasing HDL levels in Mouse via miR-33-specific antagomiRs promotes reverse cholesterol transport and suggest that it may be a promising strategy to induce atherosclerosis regression. Several months later, the same team published similar results in primates, 
more precisely African green monkeys [83]. In addition to the beneficial effects already detected in Mouse, the authors showed a strong decrease of plasma levels of very-lowdensity lipoprotein (VLDL)-associated triglycerides. This difference can tentatively be attributed to the presence of miR-33b in the SREBF1 gene of medium and large mammals and its absence in rodents. Pharmacological use of antagomiRs specific for miR-33a and miR-33b is thus able to markedly raise plasma HDL and lower VLDL triglyceride levels and therefore a promising therapeutic strategy to treat dyslipidaemias, and their induced cardiac consequences in human patients.

\section{In conclusion: MicroRNAs, a bright future?}

In the last decade, many advances have been made to decipher miRNA roles in cardiovascular development and pathogenesis. New methods have been developed in order to use them as innovative biomarkers in diagnostics, and as groundbreaking drugs in pharmacological treatments. A first, promising, clinical trial in humans is in progress right now. However, many questions remain still to be answered. Each miRNA targets up to one hundred mRNA targets, which poses significant challenges to the identification, and specific targeting, of the mRNAs that are relevant to a particular pathological process. On the other hand, this problem could also become a solution, since it is now clear that a particular family of miRNAs is associated with the same disease type [84]. So it could prove more efficient to target a predefined network of related miRNAs rather than a single one [85].

With the current pace of evolution in understanding the basic ways of miRNA action in cardiovascular development and disease, one can safely trust that these small molecules will still amaze us with more revelations in the near and not so near future.

\section{Author details}

Valérie Metzinger-Le Meuth, Eléonore M'Baya-Moutoula,

Fatiha Taibi, Ziad Massy and Laurent Metzinger

INSERM U-1088, Amiens, France

Valérie Metzinger-Le Meuth, Eléonore M'Baya-Moutoula,

Fatiha Taibi, Ziad Massy and Laurent Metzinger

Faculty of Pharmacy and Medicine, University of Picardie Jules Verne, Amiens, France

Valérie Metzinger-Le Meuth

Université Paris 13, UFR SMBH, Bobigny, France

Ziad Massy

Division(s) of Pharmacology and Nephrology, Amiens University Hospital, Amiens, France

Laurent Metzinger*

Biochemistry Laboratory, Amiens University Hospital, Amiens, France

${ }^{*}$ Corresponding Author 


\section{Acknowledgement}

This work was funded by grants from the Picardie Regional Council (MARNO-MPCC and Modulation des calcifications cardiovasculaires), including a PhD fellowship for FT and a postdoctoral fellowship for EMM.

\section{References}

[1] Bartel DP. MicroRNAs: target recognition and regulatory functions. Cell 2009;136(2) 215-233.

[2] Gommans WM, Berezikov E. Controlling miRNA regulation in disease. Methods Mol Biol 2012;822 1-18.

[3] Rangrez AY, Massy ZA, Metzinger-Le Meuth V, Metzinger, L. miR-143 and miR-145: Molecular keys to switch the phenotype of vascular smooth muscle cells, Circulation Cardiovascular Genetics 2011;4(2) 197-205.

[4] Small EM, Frost RJ, Olson EN. MicroRNAs add a new dimension to cardiovascular disease. Circulation 2010;121(8) 1022-1032.

[5] Thum T, Galuppo P, Wolf C, Fiedler J, Kneitz S, van Laake LW, Doevendans PA, Mummery CL, Borlak J, Haverich A, Gross C, Engelhardt S, Ertl G, Bauersachs J. MicroRNAs in the human heart: a clue to fetal gene reprogramming in heart failure. Circulation 2007;116(3) 258-267.

[6] Kim VN. MicroRNA biogenesis: coordinated cropping and dicing. Nature Reviews Molecular and Cellular Biology 2005;6(5) 376-385.

[7] Starega-Roslan J, Koscianska E, Kozlowski P, Krzyzosiak WJ. The role of the precursor structure in the biogenesis of microRNA. Cellular and Molecular Life Sciences 2011;68(17) 2859-2871.

[8] Guo H, Ingolia NT, Weissman JS, Bartel DP. Mammalian microRNAs predominantly act to decrease target mRNA levels. Nature 2010;466(7308) 835-40.

[9] Forman JJ, Coller HA. The code within the code: microRNAs target coding regions; Cell Cycle 2010;9(8) 1533-1541.

[10] Lee I, Ajay SS, Yook JI, Kim HS, Hong SH, Kim NH, Dhanasekaran SM, Chinnaiyan AM, Athey BD. New class of microRNA targets containing simultaneous 5'-UTR and 3'UTR interaction sites, Genome Research 2009;19(7) 1175-1183.

[11] Shin C, Nam JW, Farh KK, Chiang HR, Shkumatava A, Bartel, DP. Expanding the microRNA targeting code: functional sites with centered pairing. Molecular Cell 2010;38(6) 789-802.

[12] Griffiths-Jones S. miRBase: microRNA sequences and annotation. Current Protocols in Bioinformatics 2010 Chapter 12 Unit 12(9) 1-10..

[13] Berezikov E. Evolution of microRNA diversity and regulation in animals. Nature Reviews in Genetics 2011;12(12) 846-860.

[14] Bernardo BC, Charchar FJ, Lin RC, McMullen JR. A microRNA guide for clinicians and basic scientists: background and experimental techniques. Heart Lung Circulation 2012;21(3) 131-42. 
[15] Chen Y, Gelfond JA, McManus LM, Shireman PK. Reproducibility of quantitative RTPCR array in miRNA expression profiling and comparison with microarray analysis. BMC Genomics 2009;10 407.

[16] Xie J, Ameres SL, Friedline R, Hung JH, Zhang Y, Xie Q, Zhong L, Su Q, He R, Li M, Li H, Mu X, Zhang H, Broderick JA, Kim JK, Weng Z, Flotte TR, Zamore PD, Gao G. Longterm, efficient inhibition of microRNA function in mice using rAAV vectors. Nature Methods 2012;9(4) 403-409.

[17] Albinsson S, Skoura A, Yu J, DiLorenzo A, Fernandez-Hernando C, Offermanns S, Miano JM, Sessa WC. Smooth muscle miRNAs are critical for post-natal regulation of blood pressure and vascular function, PLoS One 2011;6(4) e18869.

[18] Boettger T, Beetz N, Kostin S, Schneider J, Kruger M, Hein L, Braun T. Acquisition of the contractile phenotype by murine arterial smooth muscle cells depends on the Mir143/145 gene cluster. Journal of Clinical Investigation 2009;119(9) 2634-2647.

[19] Cordes KR, Sheehy NT, White MP, Berry EC, Morton SU, Muth AN, Lee TH, Miano JM, Ivey KN, Srivastava D. miR-145 and miR-143 regulate smooth muscle cell fate and plasticity. Nature 2009;460(7256) 705-710.

[20] Elia L, Quintavalle M, Zhang J, Contu R, Cossu L, Latronico MV, Peterson KL, Indolfi C, Catalucci D, Chen J, Courtneidge SA, Condorelli G. The knockout of miR-143 and 145 alters smooth muscle cell maintenance and vascular homeostasis in mice: correlates with human disease. Cell Death Differentiation 2009;16(12) 1590-1598.

[21] Vo NK, Dalton RP, Liu N, Olson EN, Goodman RH. Affinity purification of microRNA133a with the cardiac transcription factor, Hand2. Proceedings of the National Academy of Sciences U S A 2010;107(45) 19231-19236.

[22] Davis-Dusenbery BN, Chan MC, Reno KE, Weisman AS, Layne MD, Lagna G, Hata. A. Down-regulation of Kruppel-like factor-4 (KLF4) by microRNA-143/145 is critical for modulation of vascular smooth muscle cell phenotype by transforming growth factorbeta and bone morphogenetic protein 4. Journal of Biological Chemistry 2011;286(32) 28097-28110.

[23] Torella D, Iaconetti C, Catalucci D, Ellison GM, Leone A, Waring CD, Bochicchio A, Vicinanza C, Aquila I, Curcio A, Condorelli G, Indolfi C. MicroRNA-133 controls vascular smooth muscle cell phenotypic switch in vitro and vascular remodeling in vivo. Circulation Research 2011;109(8) 880-893.

[24] Miano JM, Small EM. MicroRNA133a: a new variable in vascular smooth muscle cell phenotypic switching. Circulation Research 2011;109(8) 825-827.

[25] Harfe BD, McManus MT, Mansfield JH, Hornstein E, Tabin CJ. The RNaseIII enzyme Dicer is required for morphogenesis but not patterning of the vertebrate limb. Proceedings of the National Academy of Sciences U S A 2005;102(31) 10898-10903.

[26] Kanellopoulou C, Muljo SA, Kung AL, Ganesan S, Drapkin R, Jenuwein T, Livingston DM, Rajewsky K. Dicer-deficient mouse embryonic stem cells are defective in differentiation and centromeric silencing. Genes Development 2005;19(4) 489-501.

[27] Cheng B, Liu HW, Fu XB, Sun TZ, Sheng ZY. Recombinant human platelet-derived growth factor enhanced dermal wound healing by a pathway involving ERK and c-fos in diabetic rats. Journal of Dermatological Science 2007;45(3) 193-201. 
[28] Boucher JM, Peterson SM, Urs S, Zhang C, Liaw L. The miR-143/145 cluster is a novel transcriptional target of Jagged-1/Notch signaling in vascular smooth muscle cells. Journal of Biological Chemistry 2011;286(32) 28312-28321.

[29] Xin M, Small EM, Sutherland LB, Qi X, McAnally J, Plato CF, Richardson JA, BasselDuby R, Olson E.N. MicroRNAs miR-143 and miR-145 modulate cytoskeletal dynamics and responsiveness of smooth muscle cells to injury. Genes Development 2009;23(18) 2166-2178.

[30] Hergenreider E, Heydt S, Treguer K, Boettger T, Horrevoets AJ, Zeiher AM, Scheffer MP, Frangakis AS, Yin X, Mayr M, Braun T, Urbich C, Boon RA, Dimmeler S. Atheroprotective communication between endothelial cells and smooth muscle cells through miRNAs. Nature Cell Biology 2012;14(3) 249-256.

[31] Davis BN, Hilyard AC, Nguyen PH, Lagna G, Hata A. Induction of microRNA-221 by platelet-derived growth factor signaling is critical for modulation of vascular smooth muscle phenotype. Journal of Biological Chemistry, 2009;284(6) 3728-3738.

[32] Ji R, Cheng Y, Yue J, Yang J, Liu X, Chen H, Dean DB, Zhang C. MicroRNA expression signature and antisense-mediated depletion reveal an essential role of MicroRNA in vascular neointimal lesion formation. Circulation Research 2007;100(11) 1579-1588.

[33] Zampetaki A, Mayr M. MicroRNAs in vascular and metabolic disease. Circulation Research 2012;110(3) 508-522..

[34] Le Sage C, Nagel R, Egan DA, Schrier M, Mesman E, Mangiola A, Anile C, Maira G, Mercatelli N, Ciafre SA, Farace MG, Agami R. Regulation of the p27(Kip1) tumor suppressor by miR-221 and miR-222 promotes cancer cell proliferation, Embo Journal 2007;26(15) 3699-3708.

[35] Liu X, Cheng Y, Zhang S, Lin Y, Yang J, Zhang C. A necessary role of miR-221 and miR222 in vascular smooth muscle cell proliferation and neointimal hyperplasia. Circulation Research 2009;104(4) 476-487.

[36] Bauersachs J, Thum, T. Biogenesis and regulation of cardiovascular microRNAs. Circulation Research 2011;109(3) 334-347.

[37] Liu N, Bezprozvannaya S, Williams AH, Qi X, Richardson JA, Bassel-Duby R, Olson EN. microRNA-133a regulates cardiomyocyte proliferation and suppresses smooth muscle gene expression in the heart, Genes Development 2008;22(23) 3242-3254.

[38] Tatsuguchi M, Seok HY, Callis TE, Thomson JM, Chen JF, Newman M, Rojas M, Hammond SM, Wang DZ. Expression of microRNAs is dynamically regulated during cardiomyocyte hypertrophy. Journal of Molecular and Cellular Cardiology 2007;42(6) 11371141.

[39] Yang B, Lin H, Xiao J, Lu Y, Luo X, Li B, Zhang Y, Xu C, Bai Y, Wang H, Chen G, Wang $Z$. The muscle-specific microRNA miR-1 regulates cardiac arrhythmogenic potential by targeting GJA1 and KCNJ2. Nature Medicine 2007;13(4) 486-491.

[40] Terentyev D, Belevych AE, Terentyeva R, Martin MM, Malana GE, Kuhn DE, Abdellatif M, Feldman DS, Elton TS, Gyorke S. miR-1 overexpression enhances $\mathrm{Ca}(2+)$ release and promotes cardiac arrhythmogenesis by targeting PP2A regulatory subunit B56alpha and causing CaMKII-dependent hyperphosphorylation of RyR2, Circulation Research 2009;104(4) 514-521. 
[41] Bostjancic E, Zidar N, Stajer D, Glavac D. MicroRNAs miR-1, miR-133a, miR-133b and miR-208 are dysregulated in human myocardial infarction. Cardiology 2010;115(3) 163169.

[42] Ivey KN, Muth A, Arnold J, King FW, Yeh RF, Fish JE, Hsiao EC, Schwartz RJ, Conklin BR, Bernstein HS, Srivastava D. MicroRNA regulation of cell lineages in mouse and human embryonic stem cells. Cell Stem Cell, 2008;2(3) 219-229.

[43] Carè A, Catalucci D, Felicetti F, Bonci D, Addario A, Gallo P, Bang ML, Segnalini P, Gu Y, Dalton ND, Elia L, Latronico MV, Hoydal M, Autore C, Russo MA, Dorn G.W. $2^{\text {nd }}$., Ellingsen O, Ruiz-Lozano P, Peterson KL, Croce CM, Peschle C, Condorelli G. MicroRNA-133 controls cardiac hypertrophy, Nature Medicine 2007;13(5) 613-618.

[44] Horie T, Ono K, Nishi H, Iwanaga Y, Nagao K, Kinoshita M, Kuwabara Y, Takanabe R, Hasegawa K, Kita T, Kimura T. MicroRNA-133 regulates the expression of GLUT4 by targeting KLF15 and is involved in metabolic control in cardiac myocytes. Biochemical and Biophysical Research Communications 2009;389(2) 315-320.

[45] Thum T, Gross C, Fiedler J, Fischer T, Kissler S, Bussen M, Galuppo P, Just S, Rottbauer W, Frantz S, Castoldi M, Soutschek J, Koteliansky V, Rosenwald A, Basson MA, Licht JD, Pena JT, Rouhanifard SH, Muckenthaler MU, Tuschl T, Martin GR, Bauersachs J, Engelhardt S. MicroRNA-21 contributes to myocardial disease by stimulating MAP kinase signalling in fibroblasts. Nature 2008;456(7224) 980-984.

[46] Cheng Y, Ji R, Yue J, Yang J, Liu X, Chen H, Dean DB, Zhang C. MicroRNAs are aberrantly expressed in hypertrophic heart: do they play a role in cardiac hypertrophy? American Journal of Pathology 2007;170(6) 1831-1840.

[47] Patrick DM, Montgomery RL, Qi X, Obad S, Kauppinen S, Hill JA, van Rooij E, Olson EN. Stress-dependent cardiac remodeling occurs in the absence of microRNA-21 in mice. Journal of Clinical Investigation 2010;120(11) 3912-3916.

[48] van Rooij E, Sutherland LB, Thatcher JE, DiMaio JM, Naseem RH, Marshall WS, Hill JA, Olson EN. Dysregulation of microRNAs after myocardial infarction reveals a role of miR-29 in cardiac fibrosis. Proceedings of the National Academy of Sciences U S A 2008;105(35) 13027-13032.

[49] Ott CE, Grunhagen J, Jager M, Horbelt D, Schwill S, Kallenbach K, Guo G, Manke T, Knaus P, Mundlos S, Robinson PN. MicroRNAs differentially expressed in postnatal aortic development downregulate elastin via 3' UTR and coding-sequence binding sites. PLoS One 2011;6(1) e16250.

[50] Jones JA, Stroud RE, O'Quinn EC, Black LE, Barth JL, Elefteriades JA, Bavaria JE, Gorman JH 3rd, Gorman RC, Spinale FG, Ikonomidis JS. Selective microRNA suppression in human thoracic aneurysms: relationship of miR-29a to aortic size and proteolytic induction. Circulation Cardiovascular Genetics 2011;4(6) 605-613.

[51] Callis TE, Pandya K, Seok HY, Tang RH, Tatsuguchi M, Huang ZP, Chen JF, Deng Z, Gunn B, Shumate J, Willis MS, Selzman CH, Wang DZ. MicroRNA-208a is a regulator of cardiac hypertrophy and conduction in mice. Journal of Clinical Investigation 2009;119(9) 2772-2786. 
[52] van Rooij E, Sutherland LB, Qi X, Richardson JA, Hill J, Olson EN. Control of stressdependent cardiac growth and gene expression by a microRNA. Science $2007 ; 316(5824)$ 575-579.

[53] Wang K, Zhang S, Weber J, Baxter D, Galas DJ. Export of microRNAs and microRNAprotective protein by mammalian cells. Nucleic Acids Research 2010;38(20) 7248-7259.

[54] Cesana M, Cacchiarelli D, Legnini I, Santini T, Sthandier O, Chinappi M, Tramontano A, Bozzoni I. A long noncoding RNA controls muscle differentiation by functioning as a competing endogenous RNA. Cell 2011;147(4) 358-69.

[55] Wang Z, Wang DZ, Hockemeyer D, McAnally J, Nordheim A, Olson EN. Myocardin and ternary complex factors compete for SRF to control smooth muscle gene expression. Nature 2004;428 (6979) 185-189.

[56] Chen J, Yin H, Jiang Y, Radhakrishnan SK, Huang ZP, Li J, Shi Z, Kilsdonk EP, Gui Y, Wang DZ, Zheng XL. Induction of microRNA-1 by myocardin in smooth muscle cells inhibits cell proliferation, Arterioscleris Thrombosis Vascular Biology 2011;31(2) 368-75.

[57] Wang X, Hu G, Zhou J. Repression of versican expression by microRNA-143. Journal of Biological Chemistry 2010;285(30) 23241-23250.

[58] Zhang X, Azhar G, Helms SA, Wei JY. Regulation of cardiac microRNAs by serum response factor. Journal of Biomedical Science 2011;18(1) 15.

[59] Long X, Miano JM. Transforming growth factor-beta1 (TGF-beta1) utilizes distinct pathways for the transcriptional activation of microRNA 143/145 in human coronary artery smooth muscle cells. Journal of Biological Chemistry, 2011;286(34) 30119-30129.

[60] Hirai H, Verma M, Watanabe S, Tastad C, Asakura Y, Asakura A. MyoD regulates apoptosis of myoblasts through microRNA-mediated down-regulation of Pax3. Journal of Cell Biology 2010;191(2) 347-365.

[61] Kim YK, Yeo J, Ha M, Kim B, Kim VN. Cell adhesion-dependent control of microRNA decay. Molecular Cell 2011;43(6) 1005-1014.

[62] Wang GK, Zhu JQ, Zhang JT, Li Q, Li Y, He J, Qin YW, Jing Q. Circulating microRNA: a novel potential biomarker for early diagnosis of acute myocardial infarction in humans, European Heart Journal, 2010;31(6) 659-666.

[63] Lodes MJ, Caraballo M, Suciu D, Munro S, Kumar A, Anderson B. Detection of cancer with serum miRNAs on an oligonucleotide microarray. PLoS One 2009;4(7) e6229.

[64] Wang K, Zhang S, Marzolf B, Troisch P, Brightman A, Hu Z, Hood LE, Galas DJ. Circulating microRNAs, potential biomarkers for drug-induced liver injury, Proceedings of the National Academy of Sciences U S A 2009;106(11) 4402-4407.

[65] De Rosa S, Fichtlscherer S, Lehmann R, Assmus B, Dimmeler S, Zeiher AM. Transcoronary concentration gradients of circulating microRNAs. Circulation 2011;124(18) 19361944.

[66] Fichtlscherer S, De Rosa S, Fox H, Schwietz T, Fischer A, Liebetrau C, Weber M, Hamm CW, Roxe T, Muller-Ardogan M, Bonauer A, Zeiher AM, Dimmeler S. Circulating microRNAs in patients with coronary artery disease. Circulation Research 2010;107(5) 677684.

[67] Arroyo JD, Chevillet JR, Kroh EM, Ruf IK, Pritchard CC, Gibson DF, Mitchell PS, Bennett CF, Pogosova-Agadjanyan EL, Stirewalt DL, Tait JF, Tewari M. Argonaute2 com- 
plexes carry a population of circulating microRNAs independent of vesicles in human plasma. Proceedings of the National Academy of Sciences U S A 2011;108(12) 5003-5008.

[68] Goren Y, Kushnir M, Zafrir B, Tabak S, Lewis BS, Amir O. Serum levels of microRNAs in patients with heart failure. European Journal of Heart Failure 2012;14(2) 147-154.

[69] Koga Y, Yasunaga M, Takahashi A, Kuroda J, Moriya Y, Akasu T, Fujita S, Yamamoto S, Baba $\mathrm{H}$, Matsumura Y. MicroRNA expression profiling of exfoliated colonocytes isolated from feces for colorectal cancer screening, Cancer Prevention Research (Phila), 2010;3(11) 1435-1442.

[70] Wang G, Tam LS, Li EK, Kwan BC, Chow KM, Luk CC, Li PK, Szeto CC. Serum and urinary free microRNA level in patients with systemic lupus erythematosus. Lupus 2011;20(5) 493-500.

[71] Scherr M, Venturini L, Battmer K, Schaller-Schoenitz M, Schaefer D, Dallmann I, Ganser A, Eder M. Lentivirus-mediated antagomir expression for specific inhibition of miRNA function. Nucleic Acids Research 2007;35(22) e149.

[72] Surdziel E, Eder M, Scherr M. Lentivirus-mediated antagomir expression. Methods in Molecular Biology 2010;667 237-48.

[73] Lennox KA, Behlke MA. Chemical modification and design of anti-miRNA oligonucleotides. Gene Therapy 2011;18(12) 1111-1120.

[74] Obika S, Nanbu D, Hari Y, Morio KI, In Y, Ishida T, Imanishi T. Synthesis of 2'-O,4'-Cmethyleneuridine and -cytidine. Novel bicyclic nucleosides having a fixed C3'-endo sugar puckering. Tetrahedron Letters 1997;38(50) 8735-8738

[75] Baker M. RNA interference: Homing in on delivery. Nature 2010;464(7292) 1225-1228.

[76] Gambari R, Fabbri E, Borgatti M, Lampronti I, Finotti A, Brognara E, Bianchi N, Manicardi A, Marchelli R, Corradini R. Targeting microRNAs involved in human diseases: a novel approach for modification of gene expression and drug development, Biochemical Pharmacology 2011;82(10) 1416-1429.

[77] Jopling C. Liver-specific microRNA-122: Biogenesis and function, RNA Biology 2012;9(2) [Epub ahead of print].

[78] Lanford RE, Hildebrandt-Eriksen ES, Petri A, Persson R, Lindow M, Munk ME, Kauppinen S, Orum $\mathrm{H}$. Therapeutic silencing of microRNA-122 in primates with chronic hepatitis C virus infection. Science, 2010;327(5962) 198-201.

[79] Maegdefessel L, Azuma J, Toh R, Merk DR, Deng A, Chin JT, Raaz U, Schoelmerich AM, Raiesdana A, Leeper NJ, McConnell MV, Dalman RL, Spin JM, Tsao PS. Inhibition of microRNA-29b reduces murine abdominal aortic aneurysm development. Journal of Clinical Investigation 2012;122(2) 497-506.

[80] Matkovich SJ, Wang W, Tu Y, Eschenbacher WH, Dorn LE, Condorelli G, Diwan A, Nerbonne JM, Dorn GW 2nd. MicroRNA-133a protects against myocardial fibrosis and modulates electrical repolarization without affecting hypertrophy in pressureoverloaded adult hearts. Circulation Research 2010;106(1) 166-75.

[81] Yin VP, Lepilina A, Smith A, Poss KD. Regulation of zebrafish heart regeneration by miR-133. Developmental Biology 2012;365(2) 319-327.

[82] Rayner KJ, Sheedy FJ, Esau CC, Hussain FN, Temel RE, Parathath S, van Gils JM, Rayner AJ, Chang AN, Suarez Y, Fernandez-Hernando C, Fisher EA, Moore KJ. Antag- 
onism of miR-33 in mice promotes reverse cholesterol transport and regression of atherosclerosis. Journal of Clinical Investigation 2011;121(7) 2921-2931.

[83] Rayner KJ, Esau CC, Hussain FN, McDaniel AL, Marshall SM, van Gils JM, Ray TD, Sheedy FJ, Goedeke L, Liu X, Khatsenko OG, Kaimal V, Lees CJ, Fernandez-Hernando C, Fisher EA, Temel RE, Moore KJ. Inhibition of miR-33a/b in non-human primates raises plasma HDL and lowers VLDL triglycerides. Nature 2011;478(7369) 404-407.

[84] Xiao Y, Xu C, Guan J, Ping Y, Fan H, Li Y, Zhao H, Li X. Discovering dysfunction of multiple microRNAs cooperation in disease by a conserved microRNA co-expression network, PLoS One 2012;7(2) e32201.

[85] Kasinski AL, Slack FJ. Epigenetics and genetics. MicroRNAs en route to the clinic: progress in validating and targeting microRNAs for cancer therapy. Nature Reviews Cancer, 2011;11(12) 849-864. 